\title{
Developing and validating theory in ergonomics science
}

Neville A. Stanton

Department of Design

Brunel University

Egham, Surrey

TW20 OJZ, UK.

\section{Introduction to the special issue}

Ergonomics science abounds with methods and models for analysing tasks, designing devices, predicting performance, and collecting data on human interaction with artifacts. It is questionable, however, the extent to which these approaches have any sound basis in academic theory or any verifiable evidence to support their continued use. This special issue aims to report on contemporary theoretical developments and empirical validation data that support ergonomics methods and models.

Eight papers emerged from the peer review process to encapsulate the spirit of the special issue, discussing issues pertinent to the development and validation of ergonomics theory. Seven of these have been classified in table one according to the theory covered, any associated method mentioned, and the domain of application. Given the importance of context in ergonomics, it is interesting to note that research in the domains of driving and human supervisory control dominate the contributions.

Table 1. Summary of contributions to the special issue

\begin{tabular}{|l|l|l|l|}
\hline $\begin{array}{l}\text { Author(s) of } \\
\text { paper }\end{array}$ & $\begin{array}{l}\text { Ergonomics } \\
\text { theory }\end{array}$ & $\begin{array}{l}\text { Associated } \\
\text { method or model }\end{array}$ & $\begin{array}{l}\text { Domain of } \\
\text { application }\end{array}$ \\
\hline Hancock and Dias & $\begin{array}{l}\text { Field-of-safe-travel } \\
\text { and situational } \\
\text { awareness }\end{array}$ & N/A & Driving \\
\hline $\begin{array}{l}\text { Yu, Lau, Vicente } \\
\text { and Carter }\end{array}$ & $\begin{array}{l}\text { Problem solving } \\
\text { performance }\end{array}$ & $\begin{array}{l}\text { Abstraction } \\
\text { Hierarchy }\end{array}$ & $\begin{array}{l}\text { Human supervisory } \\
\text { control }\end{array}$ \\
\hline Hollnagel & $\begin{array}{l}\text { Team working } \\
\text { under time } \\
\text { constraints }\end{array}$ & $\begin{array}{l}\text { Contextual control } \\
\text { model }\end{array}$ & $\begin{array}{l}\text { Human supervisory } \\
\text { control }\end{array}$ \\
\hline Wickens & $\begin{array}{l}\text { Multiple } \\
\text { attentional } \\
\text { resources }\end{array}$ & $\begin{array}{l}\text { Multiple resources } \\
\text { performance } \\
\text { prediction }\end{array}$ & Aviation \\
\hline Young and Stanton & $\begin{array}{l}\text { Malleable } \\
\text { attentional } \\
\text { resources }\end{array}$ & $\begin{array}{l}\text { Demand, workload } \\
\text { and performance } \\
\text { curve }\end{array}$ & Driving \\
\hline Matthews & $\begin{array}{l}\text { Transactional } \\
\text { driver stress }\end{array}$ & $\begin{array}{l}\text { Driver stress } \\
\text { inventory }\end{array}$ & Driving \\
\hline Baber and Stanton & Rewritable routines & $\begin{array}{l}\text { Task analysis for } \\
\text { error identification }\end{array}$ & $\begin{array}{l}\text { Consumer products } \\
\text { and public } \\
\text { technology }\end{array}$ \\
\hline
\end{tabular}

In addition to those papers in table on, a paper from John Annett questions the relative merits for construct and criterion-referenced validity in the development of ergonomics theory. This raises the controversial point of whether construct validity alone is sufficient for ergonomics. It should be noted that construct and criterion-referenced validity are not mutually exclusive categories. 


\section{Contributions to the special issue}

A brief summary of the contributions is offered as an overview of the special issue. This is presented in the same order as the line up of papers.

Hancock and Dias point out that there are virtually no theories of ergonomics, rather theories are borrowed from other disciplines. In establishing ergonomics as a discipline in its own right, development of ergonomics theory is essential. This would help bridge the gulf between the world-as-it-should-be and the world-as-it-is. It is this perhaps, more than anything else, which will see the transition of ergonomics from a multidisciplinary, intersection to new discipline. Hancock and Dias are quick to point out that goals of ergonomics may actually be hindering progress. As a scientific discipline, ergonomics holds the moral highground, with the aim of bettering the human condition. They argue that this may be at conflict with other aims of improving system effectiveness and efficiency. No-one would argue with the aims of improved comfort, satisfaction and well-being, but the drawing of system boundaries might cause some heated debate. Hancock and Dias identify another major stumbling block for a unified ergonomics theory is the cover-all requirement: to predict all manner of systems interaction in a wide variety of contexts. It should come as no surprise that context specificity in theoretical development is the current order of the day. Despite all of these problems, Hancock and Dias are optimistic about the integration of concepts in ergonomics. As an example they cite the intersection between the field-of-safe-travel research and the work on situational awareness. The former comes from a tradition of ecological psychology whereas the latter comes from information processing theory. They argue that there is more uniting these concepts than separating them, as both theories are concerned with people's perceptions, interpretations and predictions of the world.

Yu, Lau, Vicente and Carter propose the Abstraction Hierarchy as a theory-based approach for analysing human performance in supervisory control. The Abstraction Hierarchy is offered as a five-tier meta-model of the work domain. It is a succinct expression of perspectives that can be taken on a system: from high level objectives, through control loops, to individual components. Vicente and colleagues have, in previous research, shown how the Abstraction hierarchy can be used to analyse the decision space through which people traverse in controlling systems. In this paper, Yu et al show that the Abstraction Hierarchy can also be used as a quantifiable measure of individuals cognitive coupling with the process they are controlling. In particular, detailed variances in strategy within, and between, participants are made apparent. They argue that the Abstraction Hierarchy offers a novel, and efficient, approach for interpreting control strategy.

Hollnagel argues that much of system design makes implicit assumptions about user physical, cognitive and interactive characteristics. He proposes that system designers need to more explicit about these representations, and offers the Contextual Control Model as one means of achieving this. The contextual control Model comprises four control modes: Strategic (characterised by longer-term anticipation and planning activities), Tactical (characterised by implementation of plans), Opportunistic (characterised by system driven behaviour), scrambled (characterised by trial-and-error behaviour). Hollnagel points out that the control modes are largely determined by the predictability of the environment and the amount of time available to make decisions. He proposes that the Contextual Control Model together with a representation of time 
available to perform can be used to gain insight into the design requirements for a processed-paced system.

Wickens develops multiple resources theory into a practical approach for predicting workload in situations where multiple tasks are performed concurrently. He describes the historical foundation of multiple resources theory, indicating how the structural dichotomies in input modalities and processing resources led to the now familiar multiple resources model. This model distinguishes between perceptual modalities, processing stages, processing codes and responses. Wickens presents a new methodology for predicting multiple task performance, which may be used for heuristic and computational evaluation. Though a worked example, Wickens demonstrates how overload may be predicted. This offers a considerable extension of multiple resource theory, into a predictive method.

Young and Stanton also dwell upon resource theory, to consider mental underload in automated systems. Often automation performs well in situations that the human operator can already cope with. This can mean that the human operator is underloaded. If a sudden demand is made on the human operator, they are often ill-prepared to cope. Previous explanations of poor performance with automation have considered fatigue, poor situational awareness, too much trust, vigilance decrements, and mental workload. Young and Stanton propose a theory that predicts the poor performance based on mental underload called Malleable Attentional Resource Theory. This theory posits three basic tenets: attentional resources are malleable; attentional resources are yoked to task demand; there is a lag in attentional resource expansion. Thus when demand is reduced, so the attentional resource pool shrinks to accommodate the reduced demand. Young and Stanton argue that this is cognitively efficient. If there is a sudden increase in demand on the human operator however (as there can be in semi-automated systems), the individual is unable to cope as the resource pool cannot expand quickly enough. Young and Stanton argue that Malleable Attentional Resource Theory offers a parsimonious explanation of the inverted U-shaped performance curve than does the fixed attentional resource theory.

Matthews proposes a transactional, ecological, theory of driver stress. This approach focuses on the interactions between drivers and their environment. He argues that the dynamics of this interaction are the key to understanding the differences in individual experiences of stress. Through his past research, Matthews and colleagues have identified five dimensions of driver stress: dislike of driving, aggression, fatigueproneness, hazard monitoring, and thrill seeking. The research already completed with the Driver Stress Inventory shows that the scales correlated with driving offences and violations, and that the scales generalise with different driving cultures. Further evidence supports the notion that the driver's stress state is dependent upon their appraisal of the driving tasks and the coping strategies that they bring to bear on it. The driver's personality and the driving situation influence these in turn. Matthews uses his theory of driver stress to propose transactional design intervention principles. The principles call for an understanding of how the technology affects the meaning that the driver attaches to the driving task.

Baber and Stanton present a theory of human-product interaction called Rewritable Routines, to show how user scripts and developed and adapted on-the-fly, as the transaction progresses. The idea of Rewritable Routines is that they are transitory, either becoming completely overwritten or modified. From this theory of human-product interaction, Baber and Stanton have developed a method for predicting, representing, and 
analysing the dialogue between people and products. An example is provided in the paper, which shows how the performance of novices and experts may be modelling in terms of speed and errors. The model of task flow has been used as past of an analytical prototyping procedure to assess a virtual product. Validation research suggests that the modelling is reasonably realistic, and the method certainly outperforms heuristic evaluations.

Annett asks the question of whether or not ergonomics lives up to the standards of scientific probity with regard to reliability and validity. To do this, he distinguishes between construct validity (how acceptable the underlying theory is), predictive validity (the usefulness and efficiency of the approach in predicting the behaviour of an existing or future system), and reliability (the repeatability of the results). Investigating the matter further, Annett identifies a dichotomy of ergonomics methods: analytical methods and evaluative methods. Annett argues that analytical methods (i.e., those methods that help the analyst gain an understanding of the mechanisms underlying the interaction between human and machines) require construct validity, whereas evaluative methods (i.e., those methods that estimate parameters of selected interactions between human and machines) require predictive validity. This presents an interesting debate for ergonomics, are methods really this mutually exclusive? Presumably methods that have dual roles (i.e., both analytical and evaluative, such as TAFEI), must satisfy both criteria. Annett argues that the evidence of reliability and validity is hard to come by, but this does not mean that the goal should not be pursued.

\section{Conclusions for the future of ergonomics theory}

Despite Hancock and Dias's pessimistic view regarding the current status of ergonomics theory, this special issue presents an optimistic outlook. Certainly Annett is optimistic about the role of ergonomics theory in the development of methods. Eight theories of ergonomics are presented in table one, in various stages of development. Given the main aim of TIES is to "stimulate development of theoretical foundations for the unique science of ergonomics" (Karwowski, 2000, p.1), we expect to see many more reports of theoretical development and validation coming forward. This is a start on the long road toward the Holy Grail of theoretical unification. Other strands in the special issue confirm that the journey has already begun.

\section{Reference}

Karwowski, W. (2000) Purely editorial, TIES, 1, 1-2. 